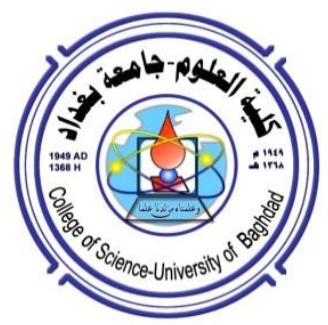

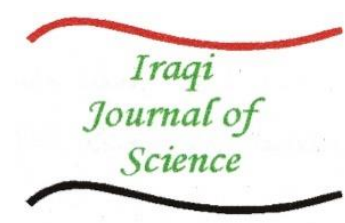

ISSN: 0067-2904

\title{
Best Regression for Eye Recognition
}

\author{
Ehsan M. Al-Bayati ${ }^{1}$, Zaid F. Makki ${ }^{2}$, Mohaemen Samir ${ }^{1}$, Fadia W. Al-Azawi ${ }^{{ }^{*}}$ \\ ${ }^{1}$ Dijlah University College, Baghdad, Iraq \\ ${ }^{2}$ Al-Nahrain Center for Strategic Studies, Baghdad, Iraq \\ ${ }^{3}$ Al-Karkh University of Science, Baghdad, Iraq
}

Received: $15 / 1 / 2021$

Accepted: 26/3/2021

\begin{abstract}
Human eye offers a number of opportunities for biometric recognition. The essential parts of the eye like cornea, iris, veins and retina can determine different characteristics. Systems using eyes' features are widely deployed for identification in government requirement levels and laws; but also beginning to have more space in portable validation world.

The first image was prepared to be used and monitored using CLAHE which means (Contrast Limited Adaptive Histogram Equalization) to improve the contrast of the image, after that the 3D surface plot was created for this image then different types of regression were used and the better one was chosen.

The results showed that power regression is better, and fitter than other fitting methods $\left(8^{\text {th }}, 7^{\text {th }}, 6^{\text {th }}, 5^{\text {th }}, 4^{\text {th }}, 3^{\text {rd }}, 2^{\text {nd }}\right)$ degree polynomial, and straight line respectively, when depending on the sum of residual squared.

The estimations of R-square demonstrated that $\left(5^{\text {th }}, 6^{\text {th }}, 7^{\text {th }}, 8^{\text {th }}\right)$ have a great proportion of variance in the model followed by (power, $4^{\text {th }}, 3^{\text {rd }}, 2^{\text {nd }}$, straight line) respectively.

The conclusion from these results is that the power regression has a better fitting than other types of fitting functions for this study and similar ones.
\end{abstract}

Keywords: Eye, CLAHE, Curve fitter

$$
\text { أفضل انحدار للتعرف على العين }
$$

$$
\begin{aligned}
& \text { احسان محسن عباس البياتي، زبلد فرهود مكي²، مهيمن سمير1 ، فاديه وضاح العزاوي3 }
\end{aligned}
$$

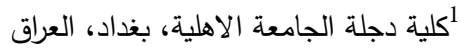

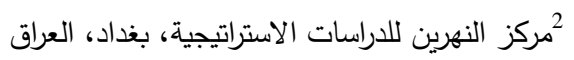

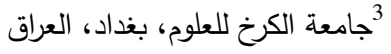

تقدم عين الإنسان عددًا من الفرص لإثبات التمييز على اساس البصمة (البايومتري). هذا البحث يحدد الأجزاء

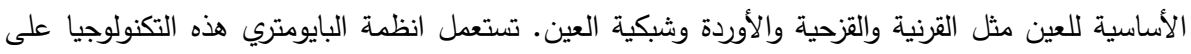

نطاق واسع لتحديد الهوية من قبل الحكومات ورجال القانون في التحقيقات على سبيل المثال.

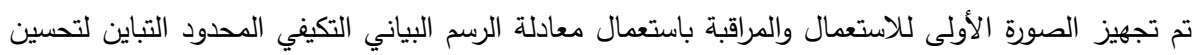

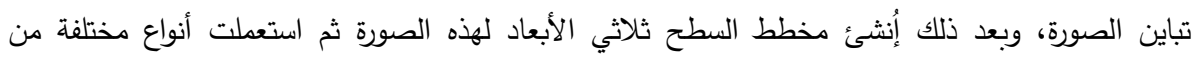




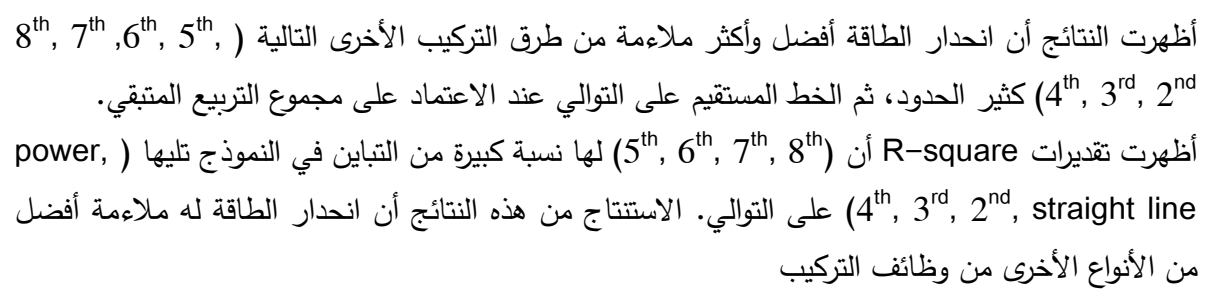

\section{1- Introduction}

It is very important to recognize different parts of the eye over a wide range of applications like Iris Recognition which plays a major role in recognizing thieves and criminals at airports. CLAHE is a technique used in this work to enhance and improve the contrast of image to get best results. Different Curve fitting functions were used in this study.

\section{1-1 The eye}

Eyes are sense organs that are particularly specialized in viewing. It is a complex assembly of light-sensitive tissues, filter, nerves, lenses, and support structures in humans [1]. There are a several chemical and physical components in the human eye. The eye strongly and heavily involved with the system of sensory nerves, which enables the brain to achieve the suitable and good decisions on how to act on the information [2]. The essential parts of the eye and the functions of them are shown in Figure 1, [3, 4]:

1- The cornea: The first part of the human eye that covers the pupil, iris, and other parts of the eye and provides eye optical power which causes refraction of light on the retina. The light entering the eye is refracted by refracting surfaces first; at the anterior surface of cornea because of curvature of cornea and due to big differences in refractive indices between air and the cornea.

2- Sclera: It is the hard-white part of the eye. This is a smooth layer outwardly and opaque, however, its inside dark colored part there are grooves which assist the ligaments of the eye to keep its shape. Sclera provides structure of the inner working parts of the eye, and it is also flexible so that the human eye can move to seek out objects as important, and it protects the eye.

3- The pupil: It is look like a dark dab amidst the eye. It changes its size automatically to control the amount of light that entering the eye.

4- The Iris: It contains the pigment which gives a color of eye.

5- Crystalline lens: the eye-lens is situated behind the iris. It is bi-convex in shape and more convex at the back sides. It is transparent and composed of different layers. The refractive index of the surrounding medium is equal to that of the surrounding shell, while the refractive indices of the inner shells gradually increase. This makes the eye- lens free from aberrations.

6- The retina: It is nerve tissue sensitive to light which converts the optical images from the optical system of the eye into electrical impulses which will be sent to brain by the optic nerve of the eye. This consists of (cones and rods) arranged in layers, which will convert light into electrical impulses. The position of the film (retina) is in the back part of the eye and is associated with the optic nerves of the eye that will transmit the optical images formed on the retina to the brain so they can be interpreted. The macula which lies at the back of the retina will help in interpreting the details of the sent object. 


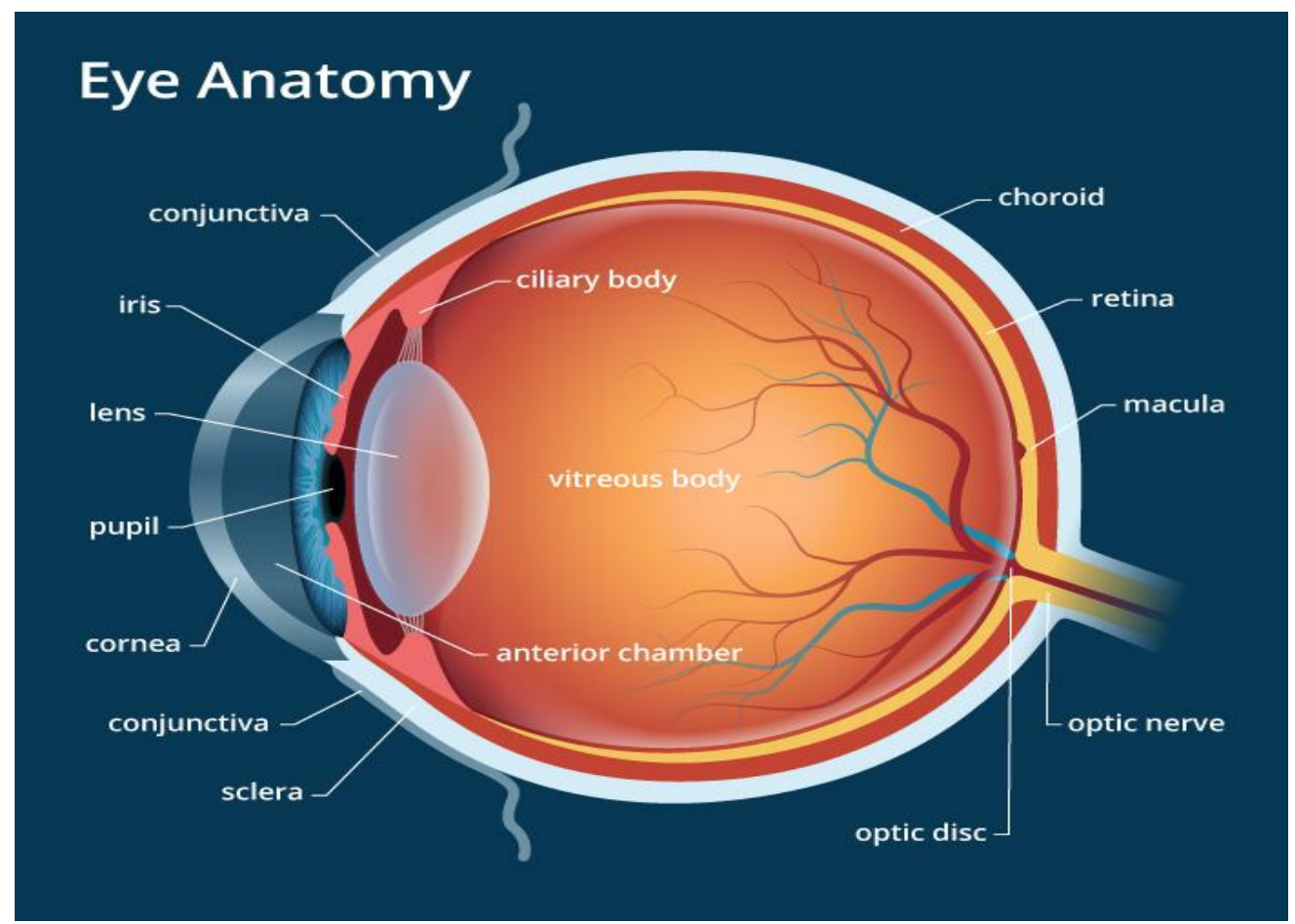

Figure 1-Essential parts of the human eyes

\section{1-2 Contrast Limited Adaptive Histogram Equalization}

CLAHE is a technique for image processing; used to enhance and improve the contrast of the images. The adaptive way computes several Histograms, each corresponding to a distinct section of the selected image, then uses them to redistribute the selected image daintiness estimations [5]. For this reason, it is suitable for improving and enhancing (The local contrast and definitions of edges in each region of the selected images) [6, and 7].

\section{1-3 Three Dimension Surface Plots}

Three Dimensions Surface Plot creates interactive surface plots from all types of the images. The luminance of each cell (pixel) in the image is interpreted as the height level of the plot [8]. Selections, and nonrectangular are supported.

The plots can be shown in different color schemes: (grayscale, original colors, and different LUT schemes. Scale, position, rotation, and perspective can be adapted. Using a smoothing option will reduce noise [9]. An adjustment of the lighting conditions enhances and improves the visibility of small differences. The surface plot gives, four different support drawing modes: (dots, lines, filled, and mesh surface) [10].

\section{1-4 Curve Fitter}

The regression analysis estimates the values of parameters that showed best fitting of the function for the observed data of this study. It proceeds from first: Making first prediction and guesses of all the parameters of the function. Second: Computing the model, and comparing it to the data set, then determine a fitting error. Third: when the fitting error is large, the CurveFitter will systematically change these parameters and returns to step 2). The loop stops when fitting accuracy is met, which may be rarely occurred. In the latter case, the procedure terminates after an imposed number of restarts or iterations [11].

Curve Fitter performs regression analysis to determine and estimate the values of parameters for (linear, nonlinear, multivariate, polynomial, exponential) functions. The regression analysis determines the values of the parameters that cause the function to best fit the observed used data. The functions of the curve fitters used in this study are shown in Table 1 [12]. 
Table 1-Curve fitter's functions used in this study

\begin{tabular}{|c|c|c|}
\hline Function & Formula & Meaning \\
\hline $\begin{array}{l}\text { Straight line (Linear } \\
\text { regression) }\end{array}$ & $Y=a+b x$ & $\begin{array}{l}\text { There are no data } \\
\text { restrictions associated with } \\
\text { this curve fit. }\end{array}$ \\
\hline $\begin{array}{l}2^{\text {nd }}-8^{\text {th }} \text { degree } \\
\text { polynomial }\end{array}$ & $Y=a+b x+c x^{2}+\ldots+\dot{i} x^{8}$ & $\begin{array}{l}\text { The more complex the } \\
\text { curvature of the data, the } \\
\text { higher the polynomial } \\
\text { order required to fit it. }\end{array}$ \\
\hline Power & $Y=a^{*} x^{\wedge} b$ & $\begin{array}{l}\text { This curve fit cannot be } \\
\text { used to fit negative data or } \\
\text { data equal to zero. }\end{array}$ \\
\hline
\end{tabular}

\section{2- Methodology of work}

Work of eye recognition system consists of image acquisition, segmentation technique, analysis of the image, feature extraction technique, and matching of extracted feature of the eye. The best approach acquires images was used here by using digital photo professional camera at the same room conditions like temperature and illumination.

\section{2-1 The proposed algorithms}

The proposed algorithm for the image processing using CLAHE and curve fitter is shown in Figure 2. The first step is the input of image in digital form. The next step is enhancing of the image using (CLAHE). After image enhancement, a curve enhancement was applied.

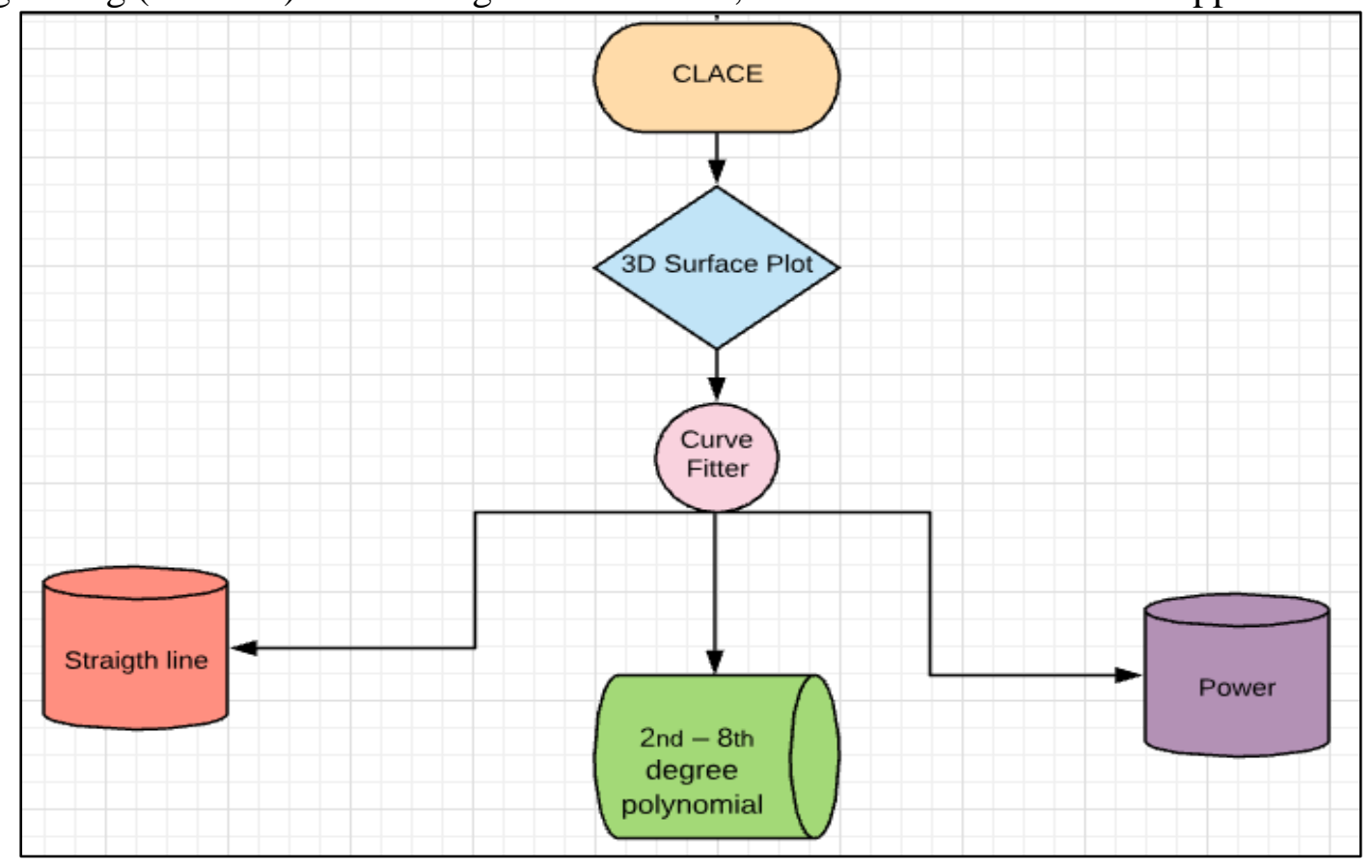

Figure 2-Schematic diagram for the proposed technique

\section{3- Results and Discussion}

The residuals squares sum due to the fitting error. Value closer to zero indicates a fit that is more suitable for prediction. The results showed that, power regression is better and fitter than the others fitting methods next $\left(8^{\text {th }}, 7^{\text {th }}, 6\right.$ th, and $\left.5^{\text {th }}\right)$ degree polynomial and straight line respectively. 
R-square measure is the square of the correlation between (the response and the predicted) values. A value closer to one indicates that a greater proportion of variance is accounted by the model. The results showed that $\left(5^{\text {th }}, 6^{\text {th }}, 7^{\text {th }}, 8^{\text {th }}\right)$ indicates a greater proportion of variance of model followed by (power, $4^{\text {th }}, 3^{\text {rd }}, 2^{\text {nd }}$, straight line) respectively.

Standard deviation, which distribution with a variation coefficient higher than 1 are considered to be high variance, whereas those with a CV lower than 1 are supposed to be lowvariance. The results are shown in Figures 3 and 4 respectively.

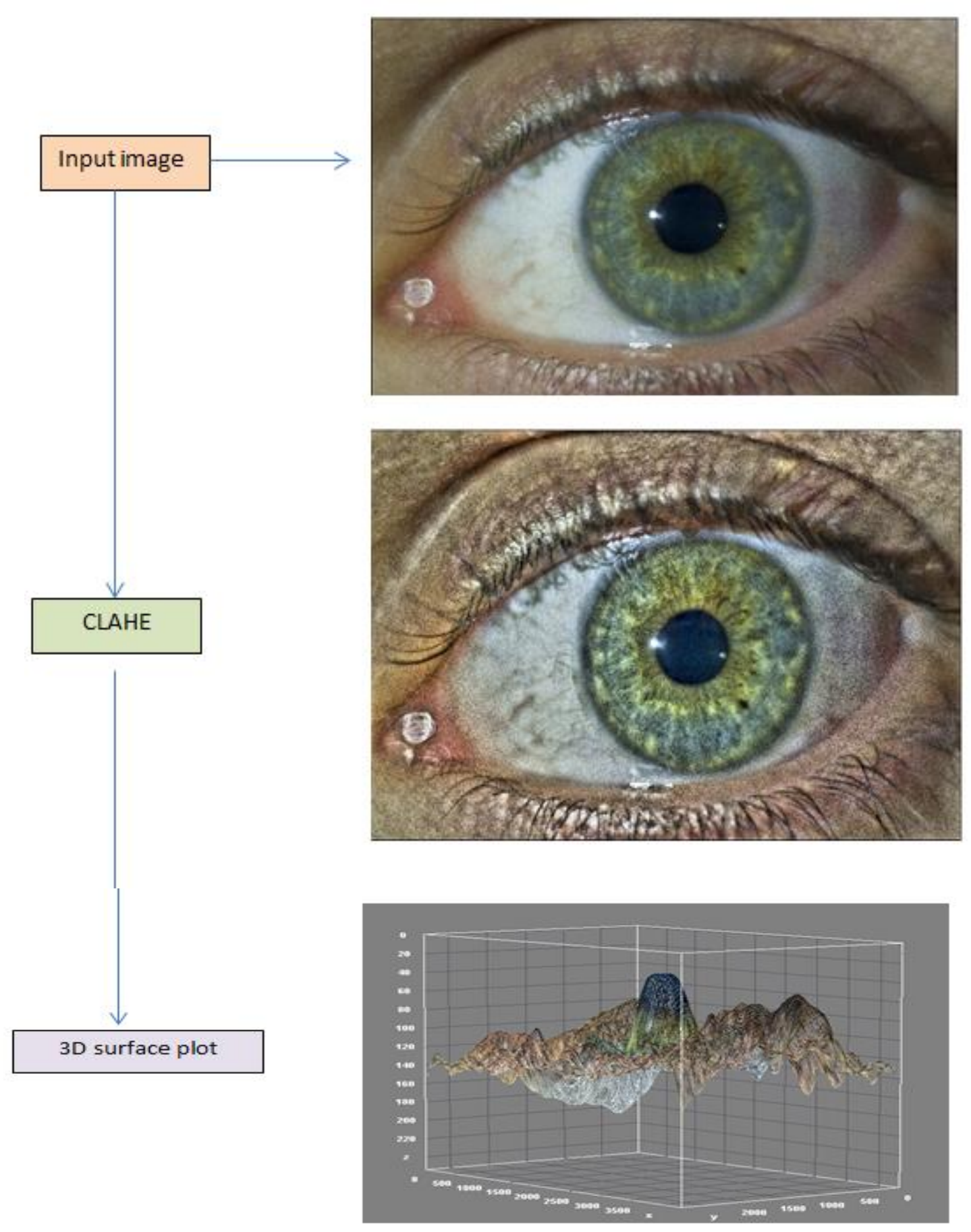

Figure 3- Visualization modes of the 3D surface plot for the selected case 

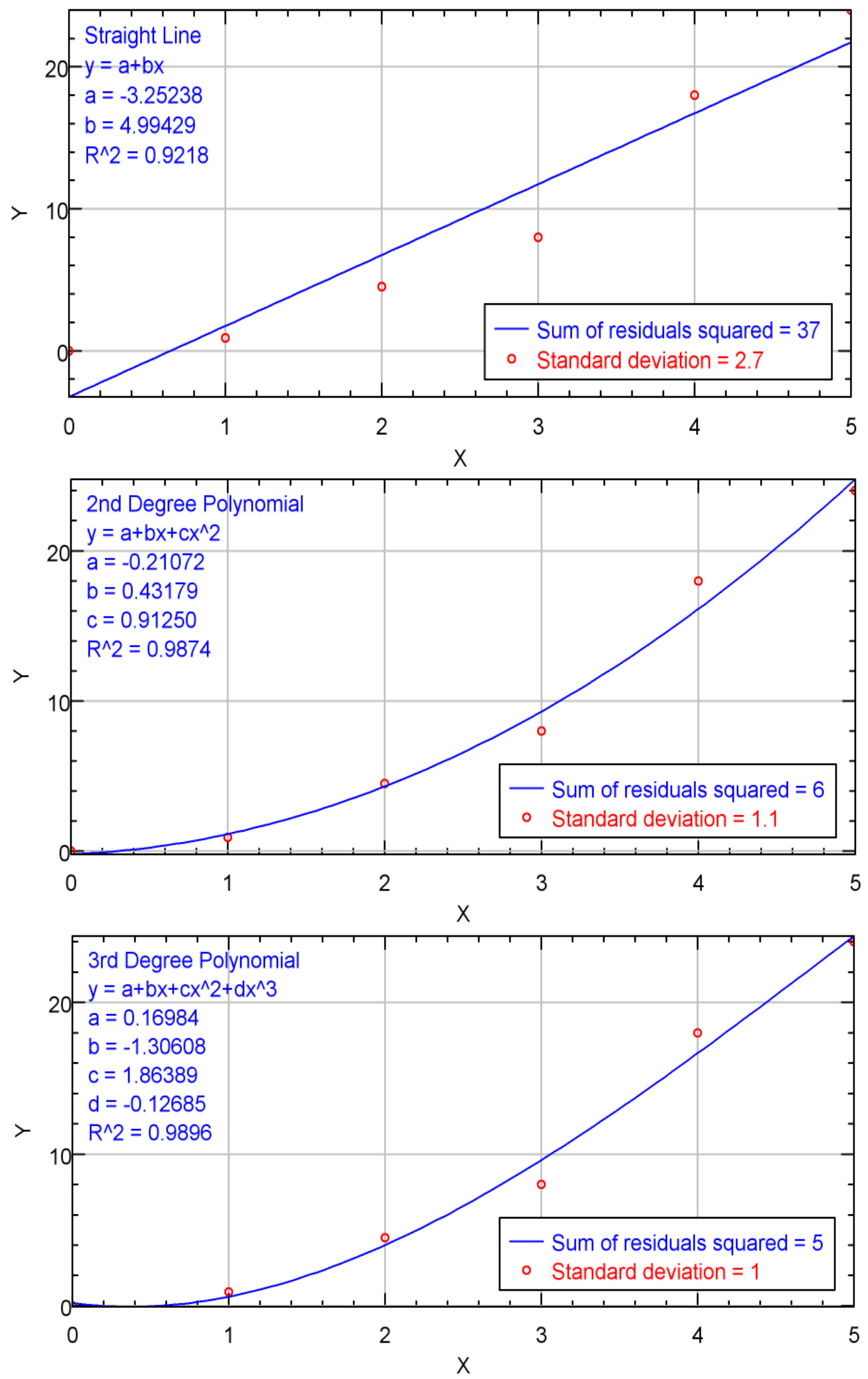

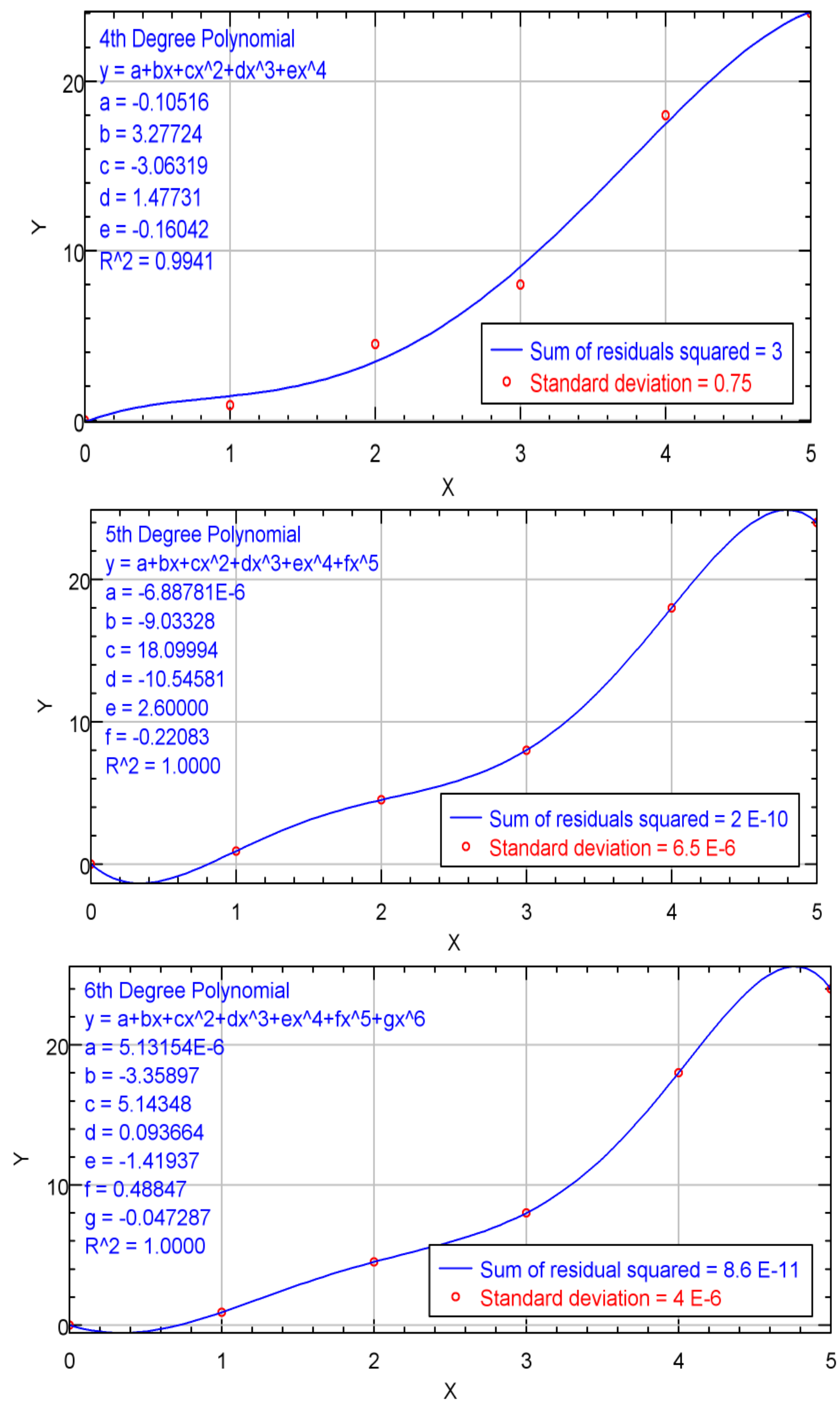

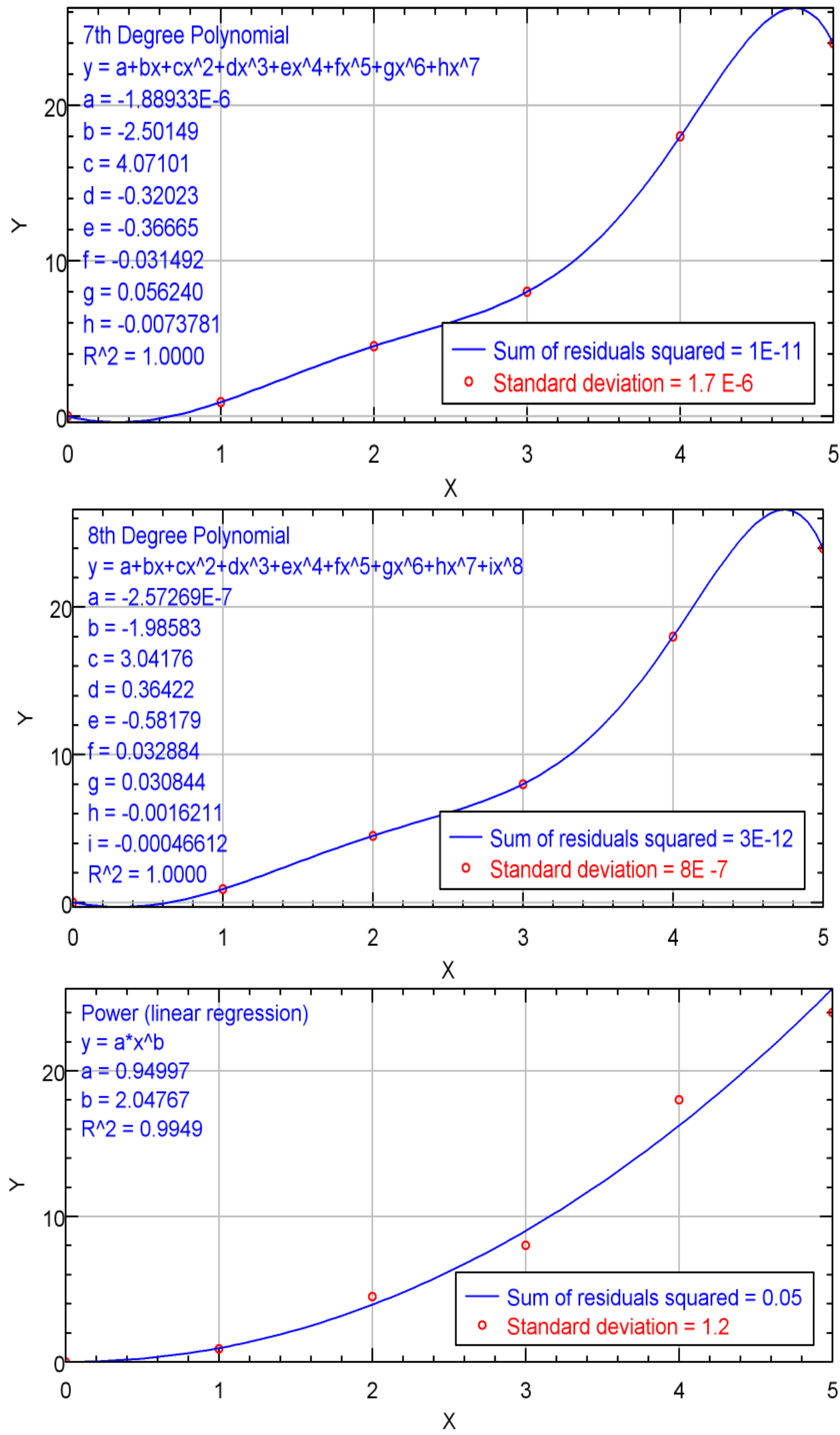

Figure 4-Sample plot diagram for Polynomial curve fit applied 


\section{4- Conclusions}

1. CLAHE has produced good results on eye image.

2. A $3 \mathrm{D}$ surface plot is a three-dimensional graph that is useful for exploring attractive reaction esteems, investigating desirable response values, and operating conditions for this work.

3. The power regression has a better fitting than the other types of fitting functions in this and similar studies.

\section{5- References}

[1] Campbell CJ, "Physiological Optics", Hagerstown, MD: Harper \& Row; 1974.

[2] Tasman W, Jaeger EA, eds., "Duane's Ophthalmology on DVD-ROM”, Philadelphia: Lippincott Williams \& Wilkins; 2012.

[3] Yanoff M, Duker JS, "Ophthalmology: Expert Consult Premium Edition”, 3rd Ed. St Louis: Mosby; 2009.

[4] Louis B. Cantor, Christopher J. Rapuano, and George A. Cioffi, "American Academy of Ophthalmology", The eye M.D. Association. Clinical optics. (2014-2015).

[5] Ali M. Reza, "Realization of the Contrast Limited Adaptive Histogram Equalization (CLAHE) for Real-Time Image Enhancement", Journal of VLSI Signal Processing, vol. 38, pp 35-44, 2004.

[6] Rafael C. Gonzalez, and Richard E. Woods, "Digital Image Processing”, 2nd edition, Prentice Hall, 2002.

[7] Hussein S. A. and Kareem M. R, " Compression and Analysis between Classic and Modern Cache Replacement Techniques", Iraqi Journal of Information Technology (IJIT), vol. 9, no.1, pp. $28-47,2018$.

[8] K. U. Barthel, "3D Surface Plot”, 2004. http://rsb.info.nih.gov/ij/plugins/surface-plot-3d.html.

[9] Lorensen WE, "Cline HE: Marching Cubes: A High-Resolution 3D Surface Construction Algorithm in SIGGRAPH '87", Proceedings of the 14th annual conference on Computer graphics and interactive techniques Volume 21. New York, NY, USA: ACM Press:163-169.

[10] Murrell P "R Graphics", Chapman \& Hall/CRC, Boca Raton, FL., 2005. ISBN 1-584-88486-X.

[11] Michael H. Kutner, Christopher J. Nachtsheim, John Neter, and William Li. "Applied Linear Statistical Models", $5^{\text {th }}$ edition. McGraw-HiliIrwin, 2005.

[12] Press, W.H., B.P. Flannery, S.A. Teukolsky, and W.T. Vetterling, "Numerical Recipes in C", 2nd Ed., 994 pp., Cambridge University Press, New York, 1992. 